\section{African fossil hominids}

Catalogue of Fossil Hominids. Part 1: Africa. (Second edition). Edited by K. P. Oakley, B. G. Campbell and T. 1. Molleson. Pp. $210+21$ plates. (British Museum Natural History: London 1977.) £12.

REVIEWING a catalogue can be likened to reviewing a telephone directory. It would take a devoted reviewer-nay, an obsessional one--to check all the facts; all one can reasonably do is comment on their presentation.

There are now three published parts of the Catalogue of Fossil Hominids. Part I deals with Africa, Part II with Europe, and Part III with the Americas, Asia and Australasia. Part I is the first to go into a second edition. All follow a similar style. Fossils are grouped by site and then, for the large sites, into anatomical subcategories. Eighteen items of information are given about each fossil, or group of fossils, varying from the exact name and location of the site to the location of the moulds for casts. The items include a very brief description of the completeness of the fossils, as well as geological, palaeontological and bibliographic information. The Catalogue is clearly intended as a source for reference and information about hominid fossils; how well does the series, and this particular volume, fulfil this role?

As a comprehensive source of information, the series has no rival. My experience is that the volumes represent a very reliable source of data. I detected remarkably few errors in this volume, and the prodigious task of checking entries and proof-reading has been carried out with considerable skill. Once one is accustomed to the layout, information is comparatively easy to retrieve. The use of a bookmarker as a key to the various items of information is an excellent idea. (Publishers of Tolstoy, Pasternak and Trollope, please note!)

1 would have welcomed clearer information about the circumstances of many of the fossil finds. Were they found 'in situ' or on the surface; and, if on the surface, how reliably can they be associated with particular horizons? Taxonomic attributions are given, but thcy tend to be hidden away between citations of original reports; perhaps they could be given a section of their own? Inevitably, the choice of which papers to cite is subjective, but I would quibble with some of the selections. It is unfortunate that the paper cited as the first report of KNM-ER 1470 does not mention the specimen in the text at all.

The inclusion of site maps is a welcome introduction, and greater use of geological sections should be encouraged, though it has to be admitted that compound sections can appear misleadingly simple. The decision to continue the use of Nomina Anatomica terms to describe the material is a wise one: even if it does lead to "ossa facie' and 'face' being used in the same sentence, it is important to base descriptions on internationally understood terms. The inclusion of photographs of so few specimens, even if they are holotypes, is of questionable value.

I had to work very hard to find even minor points of criticism in the latest volume. Fossils from Sterkfontein are catalogued within Members, but none of the references cited gives information about the definition of the Members; and in the section on Swartkrans reference is made to A4 dating, but this category of dating is not defined in the general introduction; however, these are points of detail and not serious criticisms.

There is no doubt in my mind that the quality of the whole Catalogue, and this new volume in particular, is a credit to the editors, and to the scientists who contri-

\section{Statistical techniques in biostratigraphy}

Concepts and Methods of Biostratigraphy. Edited by Erle G. Kauffman and Joseph E. Hazel. Pp. xiii +658. (Wiley: New York, London and Toronto, 1977.) £26.25; \$44.45.

So much in geology depends on good biostratigraphy that one must welcome any good new treatment of its concepts, methods and results. This weighty (in more ways than one) volume starts well with a scholarly and absorbing essay by J. M. Hancock on the history of concepts of correlation, and continues with six articles on a variety of biological concepts involving, for example, speciation, dispersal mechanisms and biogeography. There follow a further six articles on biostratigraphic methods, and the remainder of the book deals with a dozen major fossil groups. These include such excellent stratigraphic indices as graptolites, conodonts and ammonites together with a few 'jokers', such as corals and gastropods, which no respectable stratigrapher would use if he could possibly avoid it. Even more surprisingly, there is nothing on the increasingly important nannofossils and dinoflagellates, that have in recent years become extremely valuable in much oil company exploration and deep-sea drilling.

Although the book is marred somewhat by the poor, smudgy quality of many of the illustrations, the editors are to be congratulated on having persuaded so many leading palaeontologists to collaborate in producing a volume that will serve as a most useful teaching aid and reference work. If I buted cntries from individual countries. The Wenner-Gren Foundation for Anthropological Research is to be congratulated for supporting the preparation of the Catalogue. The clear layout and high quality of the presentation do credit to the publishers, who are to be commended for producing such a specialist publication at a realistic price. The Catalogue will continue to accumulate entries, and one hopes that the possibility of producing it in a loose leaf format is being explored.

My own copy of the predecessor to this new edition is so well used that it is disintegrating. I am confident the same fate will befall the new edition; I can think of no finer recommendation for a book.

Bernard Wood

Bernard Wood is Senior Lecturer in Anatomy at Middlesex Hospital Medical School, London, $U K$.

find myself more than a little resistant to the promotional enthusiasm of the blurb writer, it may be hecause I am not persuaded by what I estimate to be the editors' higher ambitions, judging from their joint preface and individual articles. Hazel wishes to promote the use of a variety of statistical techniques in biostratigraphy, but in my experience good stratigraphic marker fossils are the only crucial consideration. If they are present then statistics are unnecessary and if they are not, no amount of juggling with numbers will be of much help.

Far more interesting in my view is Kauffman's ambition to apply modern evolutionary and ecological concepts to improving correlation as exemplified by his work on the Cretaceous of the US Western Interior. Although I share his fascination with the sorts of biological and geological questions that his work raises, I feel he may perhaps be guilty of putting the cart before the hotse. Biostratigraphy is essentially an empirical subject and excellent work can be undertaken by people with little interest in, knowledge of, or talent for biological theory (one has only to think of stratigraphy's prime exemplar, William Smith). Thus, ammonites are more useful in stratigraphy than bivalves because of their much higher rate of faunal turnover, a fact recognised and utilised for well over a century. This raises an intriguing scientific question, as does, says, the existence of faunal provinces, but in both cases attempted solution of the problems. is irrelevant to correlation of strata. Good palaeobiology depends on good stratigraphy and not the other way around.

A. Hallam

A. Hallam is Professor of Geology at the University of Birmingham, UK. 